\title{
Repeated phytoextraction of four metal-contaminated soils using the cadmium/zinc hyperaccumulator Sedum plumbizincicola
}

\author{
Zhu $\mathrm{Li}^{\mathrm{a}, \mathrm{b}}$, Longhua $\mathrm{Wu}^{\mathrm{a}, *}$, Pengjie $\mathrm{Hu}^{\mathrm{a}}$, Yongming Luo ${ }^{\mathrm{a}, \mathrm{c}}$, Hao Zhang ${ }^{\mathrm{d}}$, Peter Christie ${ }^{\mathrm{a}}$ \\ ${ }^{a}$ Key Laboratory of Soil Environment and Pollution Remediation, Institute of Soil Science, Chinese Academy of Sciences, Nanjing 210008, \\ People's Republic of China \\ ${ }^{\mathrm{b}}$ University of Chinese Academy of Sciences, Beijing 100049, People's Republic of China \\ ${ }^{\mathrm{c}}$ Yantai Institute of Coastal Zone Research, Yantai 264003, People's Republic of China \\ d Lancaster Environment Centre, Lancaster University, Lancaster LA1 4YQ United Kingdom
}

\section{A R T I C L E I N F O}

\section{Article history:}

Received 7 October 2013

Received in revised form

10 February 2014

Accepted 26 February 2014

\section{Keywords:}

Phytoremediation

Metal bioavailability

Bioavailable contaminated stripping (BCS)

Diffusive gradients in thin-films (DGT)

\begin{abstract}
A B S T R A C T
A cadmium/zinc hyperaccumulator extracted metals from four contaminated soils over three years in a glasshouse experiment. Changes in plant metal uptake and soil total (aqua regia-extractable) and available metals were investigated. Plant $\mathrm{Cd}$ concentrations in a high-Cd acid soil and plant $\mathrm{Zn}$ concentrations in two acid soils decreased during repeated phytoextraction and were predicted by soil available metal concentrations. However, on repeated phytoextraction, plant $\mathrm{Cd}$ concentrations remained constant in lightly $\mathrm{Cd}$-polluted acid soils, as did plant $\mathrm{Cd}$ and $\mathrm{Zn}$ in alkaline soils, although soil available metal concentrations decreased markedly. After phytoextraction acid soils showed much higher total metal removal efficiencies, indicating possible suitability of phytoextraction for acid soils. However, DGTtesting, which takes soil metal re-supply into consideration, showed substantial removal of available metal and distinct decreases in metal supply capacity in alkaline soils after phytoextraction, suggesting that a strategy based on lowering the bioavailable contaminant might be feasible.
\end{abstract}

(c) 2014 Elsevier Ltd. All rights reserved.

\section{Introduction}

Soil metal phytoextraction is a bioremediation technique in which plants are used to remove metals from contaminated soils. Because of its merits (low cost, environmentally friendly) this technique has attracted wide interest and has been shown to be useful for slightlyto-moderately contaminated soils (McGrath et al., 2006; Li et al., 2012). However, the technique requires long periods of remediation effort and successive or numerous crops are needed to remove adequate metal from contaminated soils to achieve safe levels (Koopmans et al., 2008). Short-term remediation is not adequate for predicting the dynamics of plant metal uptake and changes in soil metals during the phytoextraction process. Some repeated cropping experiments have been conducted using hyperaccumulator species to extract metals from soils (Keller and Hammer, 2004; Liu et al., 2011) but most studies have focused on a limited range of soils or short remediation periods. It is therefore desirable to study metal changes during plant metal uptake in a wide range of soils over relatively long time periods of phytoextraction.

\footnotetext{
* Corresponding author.

E-mail addresses: lhwu@issas.ac.cn, lhwu0603@yahoo.com.cn (L. Wu).
}

Phytoextraction of metals using hyperaccumulators depends largely on the physiological capability of plants to accumulate pollutants in their shoots and on the bioavailability of the soil metals. The potential bioavailability of metals in soils can be assessed by chemical extraction and isotopic dilution methods (Menzies et al., 2007; Huang et al., 2011). However, these methods are based on equilibrium and cannot reflect the re-supply process when metals in the soil solution are depleted at the interface between the roots and the soil. The technique of diffusive gradients in thin films (DGT) continuously removes metal to the resin sink after it diffuses through a hydrogel (Davison and Zhang, 1994). It mimics the processes of metal uptake by plants that occur in the rhizosphere including soil solution metal re-supply from the solid phase at the time scale of plant metal uptake (Davison et al., 2000). The DGT technique has been used for several decades to study metal bioavailability and good correlations have been obtained between metal measured by DGT and metal in metal-tolerant plants or crops (Song et al., 2004; Tandy et al., 2011; Williams et al., 2012). Luo et al. (2010) found that metal measured by DGT is well correlated with metal in hyperaccumulators growing in soils with a series of added metal concentrations. However, detailed information about correlations between metal in hyperaccumulators and available soil metal based on equilibrium (chemical reagent-extractable) and/or 
kinetics (DGT) during the process of repeated phytoextraction is not available.

Several studies indicate that phytoextraction based on the removal of total metal would take several decades or need several repeated remediation crops, depending on the soil metal level and plant metal concentration and biomass (Van Nevel et al., 2007; Koopmans et al., 2008; Liang et al., 2009). However, it is not necessary to remove all soil metal to reduce metal toxicity and associated risks, which are mostly related to soil labile/bioavailable metal. The strategy of "bioavailable contaminated stripping" (BCS) in phytoextraction aims at removing the bioavailable metal from soils instead of depletion of the soil total metal concentrations (Hamon and McLaughlin, 1999). The evaluation of the re-supply of bioavailable metal is a vital step after phytoextraction has ceased for a successful phytoextraction based on BCS. Founded on kinetic principles, DGT can characterize the potential re-supply of available metal and could be used to evaluate the available metal removal efficiency after phytoextraction (Fitz et al., 2003). However, limited information is available in the literature about the remediation efficiency of BCS-based phytoextraction by DGT after cessation of phytoextraction.

Sedum plumbizincicola is a newly discovered cadmium and zinc hyperaccumulator (Wu et al., 2013) and has a remarkable ability to extract cadmium and zinc from contaminated soils. Field studies have indicated the high potential of using S. plumbizincicola for Cd and $\mathrm{Zn}$ phytoextraction (Wu et al., 2006, 2008). In the present study, four selected metal-contaminated soils with different soil properties and pollution levels were phytoextracted with the $\mathrm{Cd} / \mathrm{Zn}$ hyperaccumulator $S$. plumbizincicola grown in a sequence of seven successive crops over a period of three years. The objectives of the study were to examine the dynamics of metal uptake and soil metal changes, to determine the correlations between metals in the hyperaccumulator and in the soils, and to evaluate the efficiency of repeated phytoextraction based on total and bioavailable metal removal.

\section{Methods and materials}

2.1. Soil characterization

Samples of four metal-polluted soil types were collected from the top $15 \mathrm{~cm}$ of agricultural fields in different parts of China. Two acid soils were collected from Dabaoshan in Guangdong Province, south China, and Huludao in Liaoning Province, north China, and are referred to as DBS and HLD respectively. The soil from DBS is a Feaccumuli-Stagnic Anthrosol and has been polluted (lightly polluted by Cd) by metal mining activities and the soil from HLD (severely polluted by Cd) is a Hapli-Ustic Agrosol whose main pollution source is a zinc factory that has operated for several decades. The other two soils are alkaline soils which were collected from Zhujiawu and Shuanglingdong in Zhejiang Province, east China, and are labelled ZJW and SLD. They are from an area polluted by a copper smelter and the soil type is Fe-accumuliStagnic Anthrosols. All four contaminated soils were firstly air-dried and then passed through a 2-mm nylon sieve and mixed thoroughly. Portions of the sieved soils were used for determination of selected soil chemical properties and the remainder was stored for the long-term phytoextraction pot experiment. The $\mathrm{pH}$ of the phytoextracted and non-phytoextracted soils was measured with a glass electrode at a soil: water ratio of $1: 2.5$. Soil total organic carbon (TOC) was determined by the WalkleyBlack method. Soil cation exchange capacity (CEC) was determined by exchange with ammonium acetate $\left(1.0 \mathrm{~mol} \mathrm{~L}^{-1}, \mathrm{pH} 7.0\right)$ and titration with $\mathrm{HCl}$. Soil total metals were determined by atomic absorption spectrophotometry (Varian SpectrAA 220FS, Varian, Palo Alto, CA) after digestion with $\mathrm{HCl}: \mathrm{HNO}_{3}(4: 1, \mathrm{v} / \mathrm{v})$. Selected chemical properties of the contaminated soils are shown in Table 1.

\subsection{Repeated phytoextraction experiment and repeated sample collection}

The long-term phytoextraction pot experiment was carried out in a glasshouse located in Nanjing from 2008 to 2012 over seven successive crops. The maximum, minimum and average temperatures were 35,15 and $19-31{ }^{\circ} \mathrm{C}$, respectively. In summer the day temperatures are very high (sometimes about $40{ }^{\circ} \mathrm{C}$ ) in the glasshouse and the plants are moved outside where the maximum temperature is about $35^{\circ} \mathrm{C}$ ). In winter the glasshouse is heated to maintain the plant growth temperature about $15{ }^{\circ} \mathrm{C}$. The relative humidity, pan evaporation, and light regime of the glasshouse throughout the growth period were not measured. The first three harvests were from August 2008 to January 2009, from January to June 2009, and
Table 1

Chemical properties of four contaminated soils without and/or with long-term phytoextraction.

\begin{tabular}{|c|c|c|c|c|c|c|c|}
\hline \multirow[t]{2}{*}{ Soil } & \multicolumn{2}{|l|}{$\mathrm{pH}$} & \multicolumn{2}{|c|}{$\mathrm{TOC}\left(\mathrm{g} \mathrm{kg}^{-1}\right)$} & \multirow{2}{*}{$\frac{\mathrm{CEC}\left(\mathrm{cmol} \mathrm{kg}^{-1}\right)}{\mathrm{NP}}$} & \multirow{2}{*}{$\frac{\mathrm{Cd}\left(\mathrm{mg} \mathrm{kg}^{-1}\right)}{\mathrm{NP}}$} & \multirow{2}{*}{$\frac{\mathrm{Zn}\left(\mathrm{mg} \mathrm{kg}^{-1}\right)}{\mathrm{NP}}$} \\
\hline & $\mathrm{NP}^{\mathrm{a}}$ & $\mathrm{P}$ & NP & $\mathrm{P}$ & & & \\
\hline DBS & 3.71 & 3.87 & 24.3 & 23.7 & 8.31 & 0.42 & 291 \\
\hline HLD & 4.77 & 4.71 & 15.1 & 13.2 & 15.4 & 8.68 & 476 \\
\hline SLD & 7.74 & 7.71 & 28.4 & 25.7 & 18.9 & 16.9 & 1308 \\
\hline ZJW & 7.14 & 7.72 & 20.6 & 19.5 & 11.2 & 2.28 & 1201 \\
\hline
\end{tabular}

${ }^{\text {a }} \mathrm{NP}$, without phytoextraction; $\mathrm{P}$, the soil was repeatedly phytoextracted by the hyperaccumulator Sedum plumbizincicola. DBS, HLD, SLD, and ZJW are four different soils contaminated by metals.

from June 2009 to December 2009, respectively. After three successive remediation periods there was a five-month fallow period and then the next four successive crops which were grown from March to May 2010, June 2010 to May 2011, May to September 2011, and September 2011 to April 2012. The experiment had two planting treatments, namely contaminated soil with (P) and without (NP) the hyperaccumulator species S. plumbizincicola. Air-dried soil equivalent to $1.5 \mathrm{~kg}$ (oven dry basis) was placed in each $15-\mathrm{cm}$-diameter plastic pot. Each pot had six small holes in the base and a tray was placed underneath for watering. There were six replicates of the ' $P$ ' treatment and four seedlings of $S$. plumbizincicola (about $2 \mathrm{~cm}$ in height) were transplanted in each pot for each crop. There were three replicates of the 'NP' treatment without plants. $100 \mathrm{mg} \mathrm{kg}^{-1}$ of $\mathrm{N}$ (as $\mathrm{NH}_{4} \mathrm{NO}_{3}$ ), $\mathrm{P}$ and $\mathrm{K}$ (as $\mathrm{KH}_{2} \mathrm{PO}_{4}$ ) were added as basal fertilizer to each pot of the 'P' treatment of the first crop. Fertilizers were applied dissolved in $20 \mathrm{ml}$ deionized water to each pot of the remaining crops (especially to the third, fifth and seventh crops) when plant growth was slow or visible symptoms of nutrient deficiency were observed. Each pot was placed in a tray (to minimize drainage from the pot) and deionized water was applied daily to each tray during plant growth to maintain the soil water content at about $70 \%$ of soil water holding capacity (WHC) by weight in both the P and NP treatments.

The shoots were harvested from each pot when there was enough plant biomass (15-20 cm height) or the plants did not grow well because of environmental conditions (e.g. high temperatures, about $35^{\circ} \mathrm{C}$ in the summer) that were not conducive to plant growth. The length of the growing season of each crop is shown at the start of Section 2.2 above. All the plant shoots in each crop on all four soils were harvested at the same time. However, the roots of this species are very fine and it is impossible in practice to remove them quantitatively and retain them separately. After one cycle of phytoremediation, plant roots penetrated the soil less than $10 \mathrm{~cm}$ in the pots. No root mat was found either at the surface or the base of the pots. In field practice the roots remain in the soil when the shoots are harvested. All plant samples were washed with tap water three times and rinsed with deionized water three times, oven dried at $80^{\circ} \mathrm{C}$, weighed and ground.

During phytoextraction soil samples were collected after the third harvest (P-3) and the seventh harvest (P-7). A five-point sampling method was used to obtain soil samples at 'P-3' in order to avoid large changes in the soil conditions during the remediation. About $100 \mathrm{~g}$ soil was collected from each pot and mixed, then a portion of this soil was retained as sample 'P-3' and the remainder was returned to the pot. The ' $\mathrm{P}-7$ ' soil samples were collected after all the soil in each pot was mixed thoroughly so that the remediation efficiency could be calculated correctly. The soil samples from all treatments were air-dried, mixed and stored for analysis.

\subsection{DGT devices and calculation of DGT concentrations}

Standard piston DGT devices (DGT Research, Lancaster, UK) were prepared with a diffusion layer overlying a Chelex (Bio-Rad, Hercules, CA) resin layer. The diffusion layer was composed of a 0.8 -mm-thick polyacrylamide gel with agarose derivative cross-linker and a 0.13 -mm-thick $0.45 \mu \mathrm{m}$ cellulose nitrate filter.

The mass of metal accumulated $(M$ in $\mu \mathrm{g})$ in the resin gel layer of DGT was obtained by the following formula.

$M=C_{\mathrm{E}}\left(V_{\mathrm{HNO}_{3}}+V_{\text {gel }}\right) / f_{\mathrm{e}}$

Where $C_{\mathrm{E}}$ is the concentration of metal in the $1 \mathrm{M} \mathrm{HNO}_{3}$ elution solution $\left(\mu \mathrm{g} \mathrm{l}^{-1}\right)$, $V_{\mathrm{HNO}_{3}}$ is the volume of $\mathrm{HNO}_{3}$ added to the resin gel $(1 \mathrm{ml}), V_{\text {gel }}$ is the volume of the resin gel, typically $0.15 \mathrm{ml}$, and $f_{\mathrm{e}}$ is the elution factor for each metal, typically 0.8 .

The flux of metal measured by DGT $\left(F\right.$, in $\left.\mu \mathrm{g} \mathrm{cm}^{-2} \mathrm{~s}^{-1}\right)$ and the concentration of metal at the interface of the DGT device and the soil $\left(C_{\mathrm{DGT}}\right.$, in $\left.\mu \mathrm{g} \mathrm{l}^{-1}\right)$ were calculated as follows,

$F=M /(t A)$

$C_{\mathrm{DGT}}=F \Delta g / D$ 
Where $t$ is the DGT deployment time (in sec), $A$ is the contact area between soil and diffusive layer, typically $2.54 \mathrm{~cm}^{2}, \Delta g$ is the diffusive thickness $(0.094 \mathrm{~cm})$, and $D$ is the diffusion coefficient of the metal in the gel $\left(\mathrm{cm}^{2} \mathrm{~s}^{-1}\right)$.

\subsection{Metal chemical analysis}

2.4.1. Metal concentrated by DGT

The first three soil samples of NP (without phytoextraction), P-3 and P-7 were used for DGT deployment. For deployment, $30 \mathrm{~g}$ air-dried soil was weighed into a small plastic beaker and wetted to $60 \%$ field capacity by adding deionized water to equilibrate for two days. Then the soil moisture content was adjusted to $100 \%$ field capacity and the soil was mixed thoroughly using a plastic spatula until a smooth paste was formed. The soil paste was left to equilibrate for 1 day at room temperature $\left(18-20^{\circ} \mathrm{C}\right)$ before DGT deployment. The DGT devices were placed carefully on the soil paste with slight pressure to ensure complete contact between the filter membrane of each device and the soil. The acid soils (DBS and HLD) were deployed for $16 \mathrm{~h}$ at $19 \pm 1{ }^{\circ} \mathrm{C}$ and on the alkaline soil (where the metals had low availabilities) DGT devices were deployed for $24 \mathrm{~h}$. On retrieval, the surfaces of the DGT devices were jet-washed with deionized water to remove soil particles and then disassembled. $1 \mathrm{ml}$ of $\mathrm{HNO}_{3}(1 \mathrm{M})$ was added in a closed micro-vial to elute the metal from the resin gel. After retrieval of the DGT device, the paste soil was stirred and centrifuged at $3000 \mathrm{rpm}$ for $30 \mathrm{~min}$ to collect the soil solution. The supernatant was syringe-filtered using $0.45 \mu \mathrm{m}$ disposable polysulfone filter assemblies and acidified using $10 \mu \mathrm{l}$ of $5 \mathrm{M} \mathrm{HNO}_{3}$ in $1 \mathrm{ml}$. Eluted metals and metals in the soil solution were measured by ICP-MS (Varian Ultramass, Palo Alto, CA) within various calibration ranges after appropriate dilution, using $\mathrm{Rh}$ as internal standard.

\subsubsection{Metals extracted by chemical agents}

As in DGT deployment, the first three replicates of NP, P-3 and P-7 were used for metal extracted by $0.01 \mathrm{M} \mathrm{CaCl}_{2}$ and $1 \mathrm{M} \mathrm{NH}_{4} \mathrm{OAc}$. The methods were as follows.

Air-dried soil ( $2 \mathrm{~g}$ ) was extracted with $0.01 \mathrm{M} \mathrm{CaCl}_{2}$ (soil: extractant ratio 1: 10) by shaking at $19{ }^{\circ} \mathrm{C}$ for $2 \mathrm{~h}$, then centrifuging ( $10 \mathrm{~min}$ at $3000 \mathrm{rpm}$ ) and filtering. Cadmium and $\mathrm{Zn}$ concentrations in the supernatant were measured by ICP-MS (Varian Ultramass) within various calibration ranges using $\mathrm{Rh}$ as internal standard. Air-dried soil $\left(2 \mathrm{~g}\right.$ ) was extracted with $1.0 \mathrm{M} \mathrm{NH}_{4} \mathrm{OAc}$ (soil: extractant ratio 1: 5) by shaking at $25^{\circ} \mathrm{C}$ for $16 \mathrm{~h}$, then centrifuging ( $10 \mathrm{~min}$ at $3000 \mathrm{rpm}$ ) and filtering. Cadmium and $\mathrm{Zn}$ concentrations in the supernatant were determined by atomic absorption spectrophotometry (Varian SpectrAA 220FS; Varian, Palo Alto, CA).

\subsubsection{Determination of metals in soil and plant samples}

Soil total heavy metal concentrations were determined by atomic absorption spectrophotometry (Varian SpectrAA 220FS, 220Z; Varian, Palo Alto, CA) after digestion of $0.25-\mathrm{g}$ samples with $12 \mathrm{ml}$ of $\mathrm{HCl}: \mathrm{HNO}_{3}(4: 1, \mathrm{v} / \mathrm{v})$. Plant samples $(0.25 \mathrm{~g})$ were digested using a mixture of $6 \mathrm{ml} \mathrm{HNO}_{3}$ and $4 \mathrm{ml} \mathrm{HClO}_{4}$ and the metals were also determined by AAS. Replicate samples, blanks, and a certified reference material (GBW07401, provided by the Institute of Geophysical and Geochemical Exploration, Langfang, Hebei province, China) were included in all analyses for quality control. All chemicals used were of analytical reagent grade and the reference material results obtained by the methods described above were within the certified ranges.

\subsection{Statistical analysis}

Statistical analysis was performed using one-way analysis of variance (ANOVA) with Duncan's multiple range test at the $5 \%$ level used to compare mean values, and linear correlations between metal in the plants (the first, fifth, and seventh crops) and soil available metal extracted by $\mathrm{NH}_{4} \mathrm{Ac}$ and $\mathrm{CaCl}_{2}$, and DGT (NP, P-3, P-7) were conducted using the SPSS software package version 16.0 for Windows. Data are presented as mean \pm standard error of the mean (SEM).

\section{Results}

\subsection{Plant biomass and metal concentrations in each crop}

The plant biomass of each crop in the repeated phytoextraction sequence is listed in Table 2. The plants grew well in the four contaminated soils except for the fourth and sixth crops which produced very little biomass in all four soils. This was mainly due to the inappropriate transplanting time and the high temperatures experienced during the growing season.

The concentrations of $\mathrm{Zn}$ and $\mathrm{Cd}$ in the plant shoots of each crop are shown in Fig. 1. Shoot $\mathrm{Zn}$ concentrations of plants growing in the acid soils were much higher than in the alkaline soil. The highest $\mathrm{Cd}$ concentrations were found in plants growing in the acid soils from HLD followed by SLD with high soil Cd levels, followed by ZJW and DBS. As the phytoextraction period increased the shoot $\mathrm{Zn}$ concentrations in plants growing in DBS and HLD and the Cd
Table 2

Shoot biomass of plants growing in four contaminated soils at each harvest (g pot $\left.{ }^{-1} \mathrm{DW}\right)$.

\begin{tabular}{lllll}
\hline Harvest & DBS & HLD & SLD & ZJW \\
\hline First & $8.44 \pm 0.51 \mathrm{a}$ & $12.4 \pm 1.1 \mathrm{a}$ & $14.6 \pm 1.3 \mathrm{~b}$ & $11.8 \pm 0.9 \mathrm{~b}$ \\
Second & $3.04 \pm 0.19 \mathrm{~b}$ & $9.58 \pm 0.35 \mathrm{a}$ & $10.2 \pm 0.9 \mathrm{~b}$ & $8.53 \pm 0.98 \mathrm{~b}$ \\
Third & $3.10 \pm 0.52 \mathrm{~b}$ & $5.63 \pm 0.73 \mathrm{~b}$ & $8.85 \pm 0.61 \mathrm{~b}$ & $8.72 \pm 1.23 \mathrm{~b}$ \\
Fourth & $1.21 \pm 0.12 \mathrm{c}$ & $1.55 \pm 0.11 \mathrm{c}$ & $0.73 \pm 0.04 \mathrm{c}$ & $1.21 \pm 0.12 \mathrm{c}$ \\
Fifth & $9.07 \pm 0.62 \mathrm{a}$ & $9.44 \pm 0.38 \mathrm{a}$ & $8.47 \pm 0.77 \mathrm{~b}$ & $12.1 \pm 1.1 \mathrm{~b}$ \\
Sixth & $2.41 \pm 0.23 \mathrm{~b}$ & $1.10 \pm 0.14 \mathrm{c}$ & $1.38 \pm 0.34 \mathrm{c}$ & $1.34 \pm 0.36 \mathrm{c}$ \\
Seventh & $10.0 \pm 0.9 \mathrm{a}$ & $16.1 \pm 0.9 \mathrm{a}$ & $20.4 \pm 0.3 \mathrm{a}$ & $17.2 \pm 0.9 \mathrm{a}$ \\
\hline
\end{tabular}

Data are mean values $\pm \mathrm{SE}(n=6)$. Data with different letters in the same column indicate significant difference at the 5\% level. DBS, HLD, SLD, and ZJW are four different soils contaminated by metals.

concentrations in the plants in HLD soil decreased markedly except for the fourth and sixth crops whose biomass was very small (Fig. 1A, B). However there was no discernible decreasing trend in shoot $\mathrm{Zn}$ and $\mathrm{Cd}$ during phytoextraction of the alkaline soils (ZJW and SLD) or in shoot Cd in acid soil DBS with its low total Cd concentration. On the contrary, there tended to be a slight increase in the later crops compared with the first few crops.

The average daily uptake (ADP) of the metals was calculated (biomass multiplied by concentration and then divided by growth time (d)) in each crop except crops four and six (which did not grow well) because the plant metal concentrations can vary according to biomass and growth stage. The ADP of $\mathrm{Zn}$ in DBS and HLD and $\mathrm{Cd}$ in HLD clearly decreased during phytoextraction but $\mathrm{Zn}$ and $\mathrm{Cd}$ in the alkaline soils and Cd in DBS showed no decreasing trend during phytoextraction (Fig. 1C, D).

\subsection{Total and available metals and metal supply}

The $\mathrm{Zn}$ and $\mathrm{Cd}$ concentrations in the soils without phytoextraction (NP) and the soils after three crops and seven crops of phytoextraction are shown in Fig. 2. Both soil $\mathrm{Zn}$ and soil $\mathrm{Cd}$ decreased markedly after remediation. The largest decreases occurred in acid soil (HLD) with high levels of metals and after phytoextraction the decreases in $\mathrm{Cd}$ and $\mathrm{Zn}$ were from 8.68 to 0.93 and 476 to $229 \mathrm{mg} \mathrm{kg}^{-1}$, respectively. Compared to the NP soil, the Zn concentrations in P-7 soils from DBS, HLD, SLD and ZJW decreased by $37,52,12$, and $19 \%$, respectively, and Cd decreased by $64,89,37$, and $38 \%$.

In the present study the available soil metals were evaluated by the $\mathrm{NH}_{4} \mathrm{OAc}$ - and $\mathrm{CaCl}_{2}$-extractable fractions and by DGT. After phytoextraction with 7 crops the available $\mathrm{Zn}$ and $\mathrm{Cd}$ fractions showed a large decline in all four soils (Fig. 3). Compared to NP soils, after seven remediation crops the decreases in $\mathrm{NH}_{4} \mathrm{OAc}$ extractable Zn were 97, 98, 30 and 58\% in DBS, HLD, SLD and ZJW, respectively, and Cd decreased by $95,98,57$, and $41 \%$. The equivalent values of $0.01 \mathrm{M} \mathrm{CaCl}_{2}$-extractable $\mathrm{Zn}$ were $92,94,24$, and $27 \%$ for DBS, HLD, SLD, and ZJW and for Cd the decreases were 87, 96, 68, and $60 \%$. In comparison, the decreases in metals by DGT were much larger, from $82 \%$ ( $\mathrm{Zn}$ in SLD) to $99 \%$ (Cd in HLD) (Fig. 3). However, it should be noted that the metal availability of DBS soil evaluated by DGT might be underestimated because the soil pH was $<4$ (Zhang and Davison, 1995).

The ratio of $C_{\mathrm{DGT}}$ to the metal concentration in the soil solution, $R$ can be used to indicate the metal supply capacity. $R$ values were different in the four contaminated soils and changed to varying extents after phytoextraction (Fig. 4). For Zn, the DBS soil had a small $R$ value $(<0.2)$, indicating poor resupply from the solid phase, with little change during phytoextraction. The $R$ value for HLD soil was higher than that for the DBS soil before phytoextraction and increased substantially from $\sim 0.3$ to 0.8 . The calcareous soils (SLD 

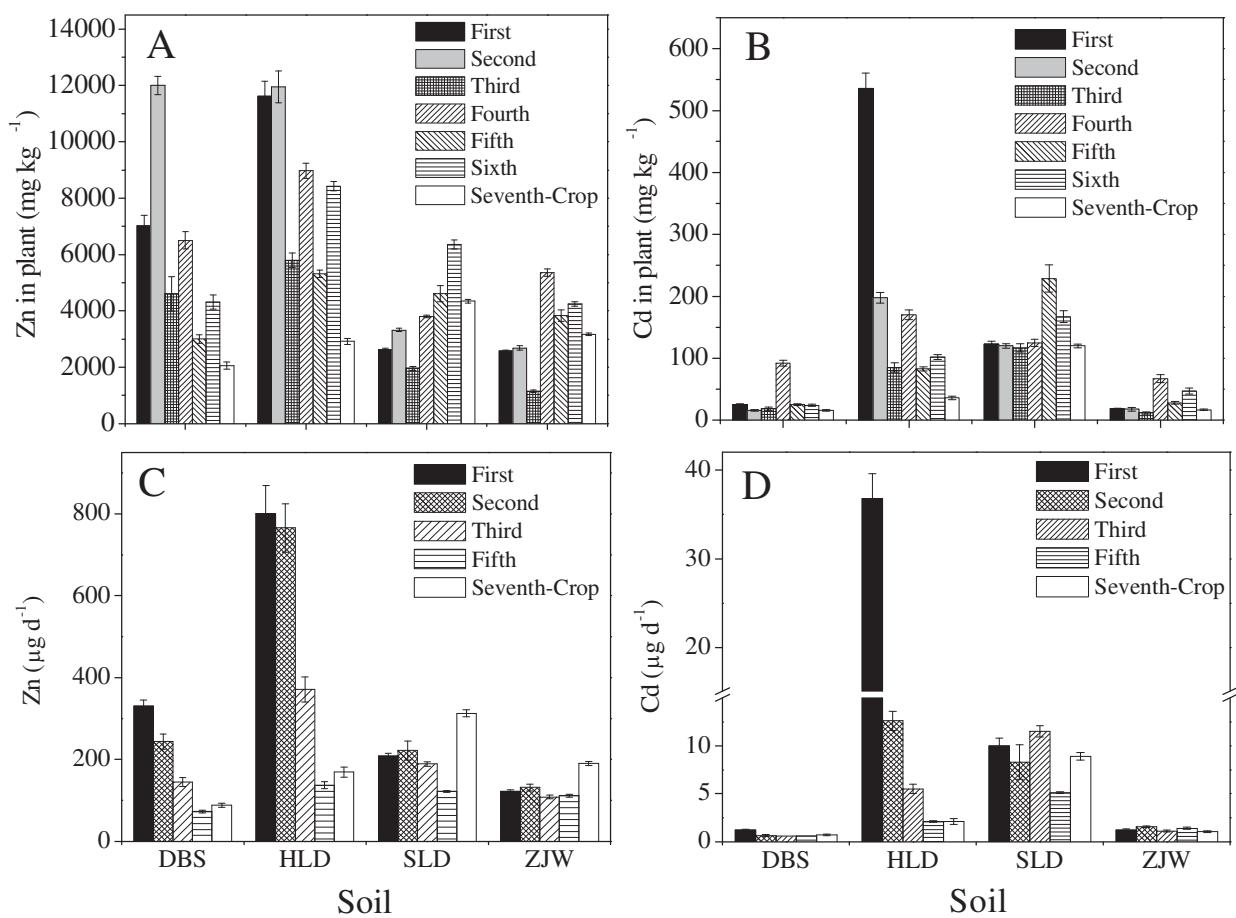

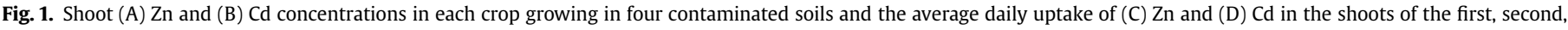

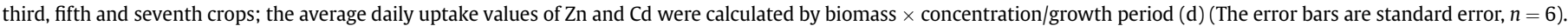

and ZJW) had high $R$ values in the treatment of "NP" and a clear increasing trend was observed during phytoextraction. $R$ values for $\mathrm{Cd}$ showed similar trends to those for $\mathrm{Zn}$, but values were lower for HLD, ZJW, and SLD soils.

\subsection{Correlation between plant metal and soil available metal}

Because the plants grew poorly in the fourth crop the metals in the first, fifth and seventh crops were used to calculate correlations with available metal in NP, P-3 and P-7 soils. The correlation between the logarithmically transformed plant shoot metal and the soil available metal evaluated by $\mathrm{NH}_{4} \mathrm{Ac}-/ \mathrm{CaCl}_{2}$-extracable fractions and DGT are shown in Figs. 5 and 6. Available $\mathrm{Zn}$ in the acid soils (DBS and HLD) evaluated by all three methods had good positive linear correlation with plant $\mathrm{Zn}$, and the correlation coefficients $\left(R^{2}\right)$ ranged from 0.92 to 0.98 . However, similar correlations were not found in alkaline soils (SLD and ZJW). In the case of Cd the acid soil with high Cd content (HLD) showed a positive linear relationship between available $\mathrm{Cd}$ and shoot $\mathrm{Cd}\left(R^{2}>0.93\right)$, but in the acid soil DBS with low Cd content a weak positive relationship between plant $\mathrm{Cd}$ and soil available $\mathrm{Cd}$ was found; similar trends were found for $\mathrm{Zn}$ and in the alkaline soils the shoot $\mathrm{Cd}$ could not be predicted by the soil available $\mathrm{Cd}$.

\section{Discussion}

\subsection{Metal uptake by plant during repeated phytoextraction}

Metal uptake from the soil by plants depends largely on both plant physiological properties (e.g. metal absorption by the roots, translocation and accumulation in the plant) and soil characteristics (e.g. metal concentrations, soil $\mathrm{pH}$, and soil components) regulating the amount of metal available to plants (Yanai et al., 2006; Kirkham, 2006; Rascio and Navari-Izzo, 2011; Muhammad et al., 2012). Hyperaccumulators are species that have high ability to take up metals by the roots and accumulate them in the aerial
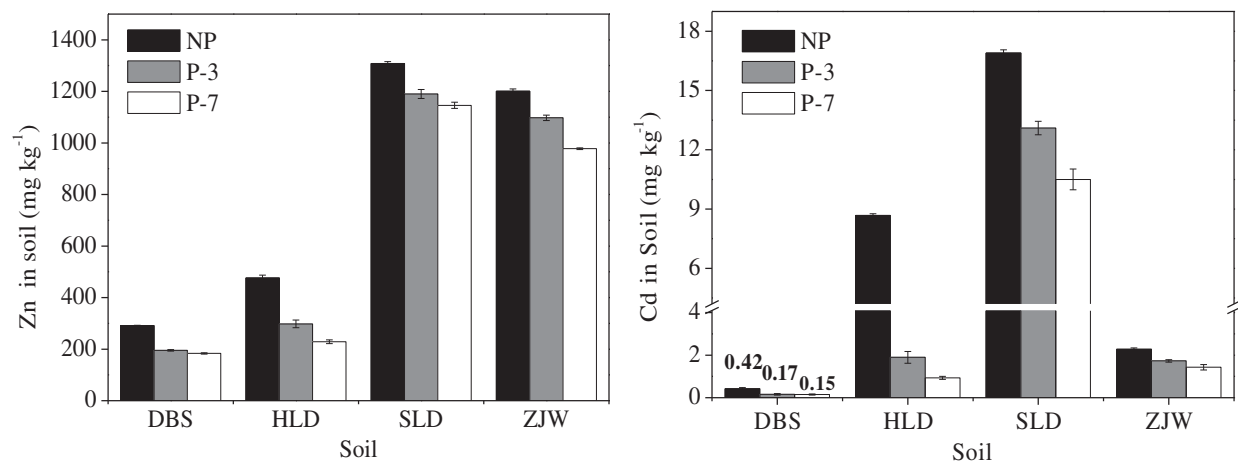

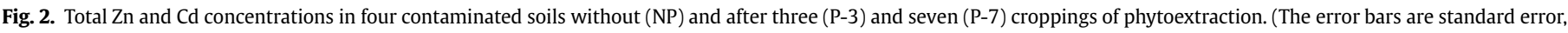
$n=3$ ). 

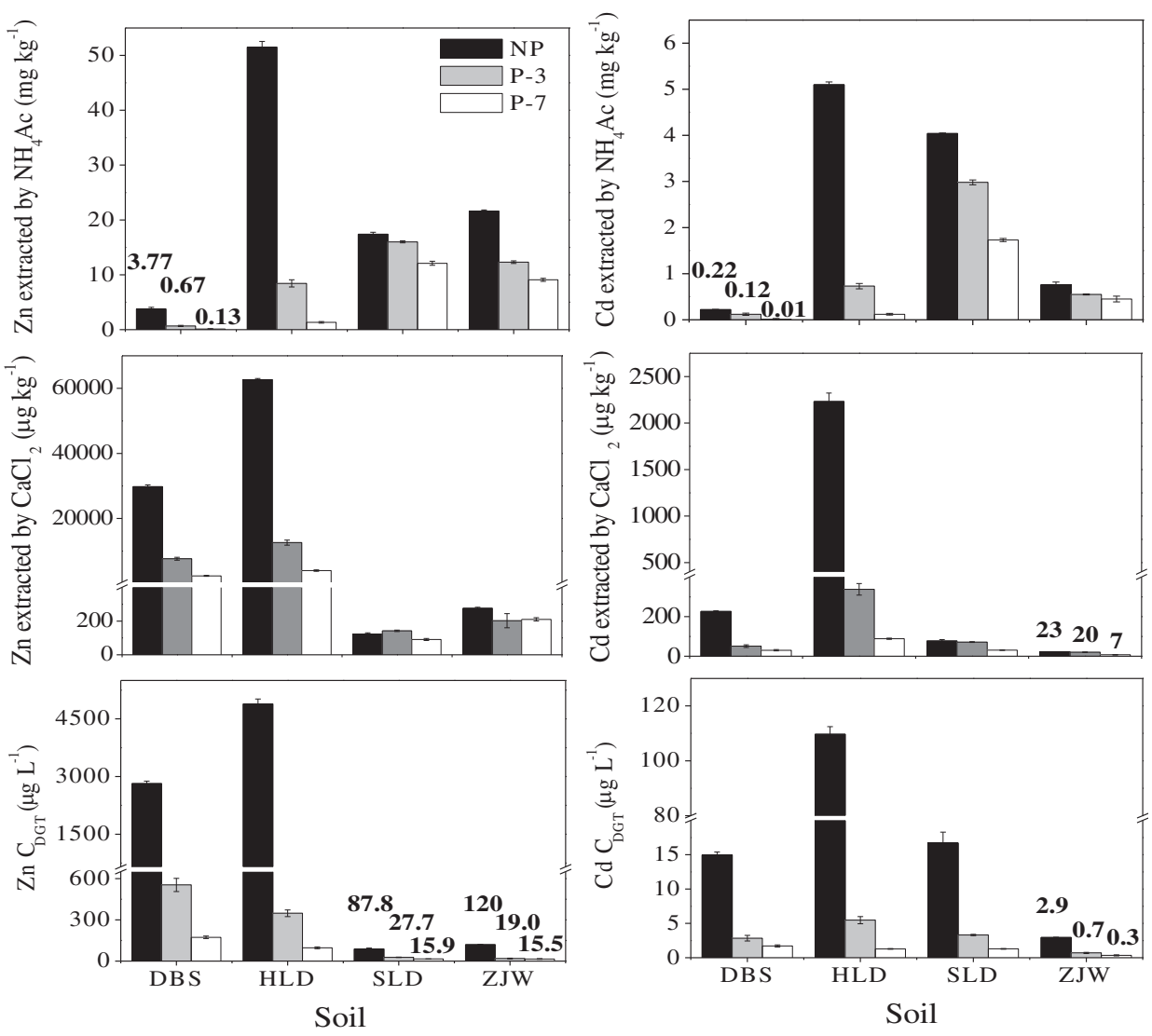

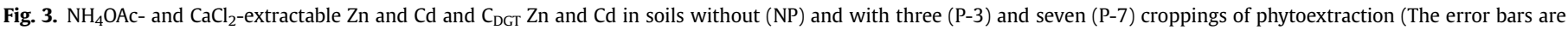
standard error, $n=3$ ).

parts without showing phytotoxic effects (Rascio and Navari-Izzo, 2011). In the present study the Cd/Zn-hyperaccumulator S. plumbizincicola was used to extract metals from soils with different physicochemical properties and pollution levels using a sequence of seven successive crops. Although the total $\mathrm{Zn}$ concentrations in the acid soils (DBS and HLD) were several times lower than in the alkaline soils (ZJW and SLD) (Table 1), the highest shoot $\mathrm{Zn}$ and $\mathrm{Cd}$ concentrations were found in the first crop in the acid soils, with concentrations of up to 12,000 and $536 \mathrm{mg} \mathrm{kg}^{-1}$, respectively (Fig. 1). This indicates that much higher percentages of the metals in acid soils were available for plant uptake during the growing season than in the alkaline soils and soil available metal had an important effect on metal uptake given the wide range of shoot metal concentrations in the different soils.

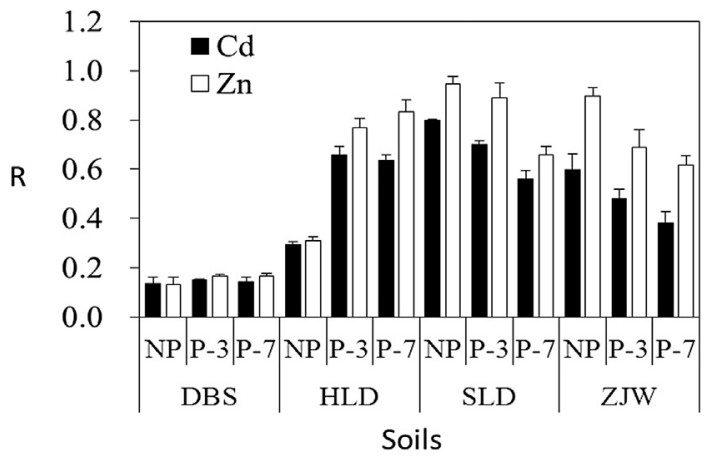

Fig. 4. $R$ values in soils without (NP) and with three (P-3) and seven (P-7) croppings of phytoextraction (The error bars are standard error, $n=3$ ).
As expected in this study, with prolonged periods of phytoextraction shoot $\mathrm{Zn}$ concentrations in the acid soils and plant $\mathrm{Cd}$ in the soil from HLD showed visible decreasing trends (Fig. 1) with the exception of the fourth and sixth crops (very small shoot biomass, Table 2), associated mainly with decreasing available metal fractions during phytoextraction (Fig. 3). However, shoot $\mathrm{Zn}$ and $\mathrm{Cd}$ in the alkaline soils and shoot Cd in DBS showed no large decrease and sometimes a slight increase in the later crops (Fig. 1). Both shoot biomass and growing time differed among the crops and this would have influenced the metal concentrations in the shoots. When this effect was taken into consideration by calculating the average metal daily uptakes (ADP) they showed similar trends to the shoot metal concentrations (Fig. 1). ADP was slightly low in the fifth crop in SLD soil (mainly because of negligible summer plant growth by the fifth crop and high temperatures), and conversely without growing in summer the seventh crop had higher ADP values. The absence of a decrease in shoot metal uptake was not consistent with the large decrease in soil available metal fractions after phytoextraction (Fig. 3). There are some possible explanations for this. First, hyperaccumulators have the ability to actively enhance plant metal uptake by mechanisms such as the excretion of organic materials by the roots. This rhizosphere function has been found in the $\mathrm{Ni}$ hyperaccumulator Thlaspi goesingense (Puschenreiter et al., 2005) and organic compounds derived from the rhizosphere of the hyperaccumulator Sedum alfredii can decrease Cd and Zn sorption on the soil matrix (Li et al., 2011). In alkaline soils metal in the soil solution is low because of the high $\mathrm{pH}$ and the metal released from soil solid fractions might make the major contribution to plant metal uptake. Studies have indicated that metal released into solution would be much higher with the rhizosphere function than 

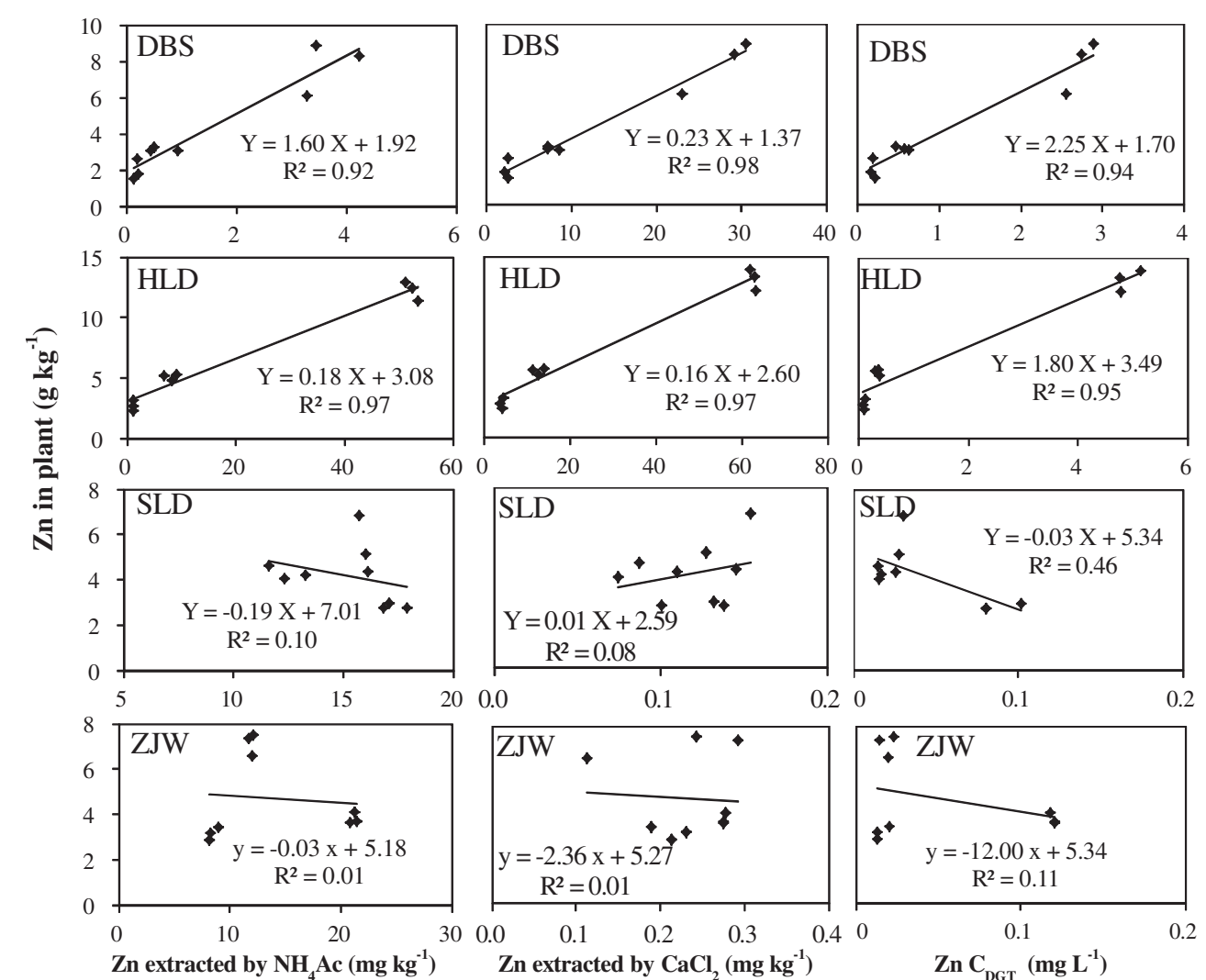

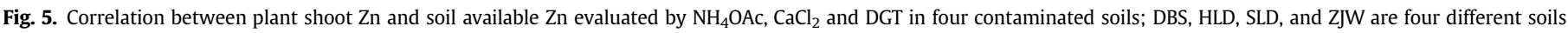
contaminated by metals.
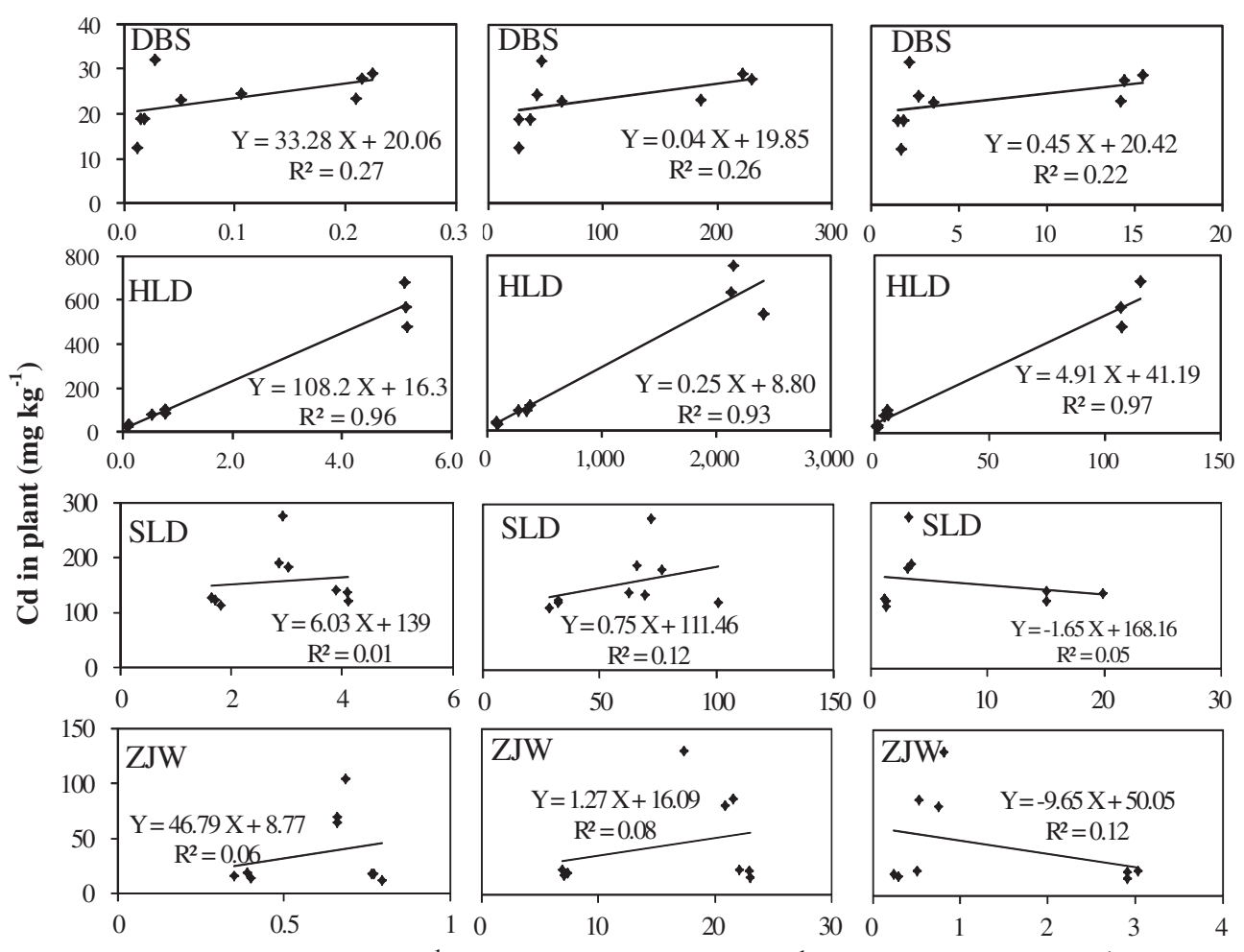

Cd extracted by $\mathrm{NH}_{4} \mathrm{Ac}\left(\mathrm{mg} \mathrm{kg}^{-1}\right) \quad \mathrm{Cd}$ extracted by $\mathrm{CaCl}_{2}\left(\mu \mathrm{g} \mathrm{kg}^{-1}\right)$

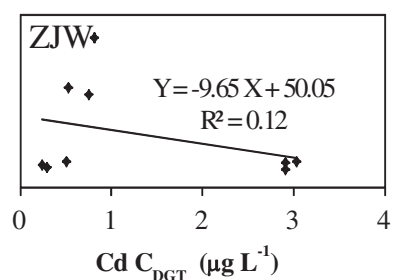

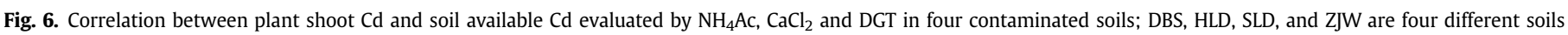
contaminated by metals. 
the metal released without rhizosphere activity (Degryse et al., 2009). Thus, in the present study the release of metal from the soil solid fraction by the root exudates of the hyperaccumulator may have determined the shoot metal concentrations. In addition, root foraging for metals has been demonstrated in some hyperaccumulators (Whiting et al., 2000; Liu et al., 2010) and this may also play a role in maintaining plant metal concentrations. Moreover, shoot metals can also be limited by root metal absorption and/ or root-to-shoot translocation. These two processes in hyperaccumulators mostly involve the metal membrane transporter proteins (Rascio and Navari-Izzo, 2011). Assuncao et al. (2001) report that the expression of metal-transporter in Thlaspi caerulescens responded to $\mathrm{Zn}$ and the calamine soil induced much higher transporter (ZTP1) expression in the plant than did serpentine or normal soils. This may indicate that metal concentrations in the plant growth environment can regulate the expression of transporter proteins in the plant and then regulate shoot metal concentrations. However, at present we cannot accurately assess which mechanism was the main explanation in our experiment and this requires further study.

\subsection{Plant metal correlated with soil available metal during repeated phytoextraction}

Shoot biomass and metal concentration will be the most important factors for plant metal removal from contaminated soils and this can further affect the phytoextraction efficiency. During phytoextraction soil available metal fractions will decrease and this may lower plant metal uptake by the next crop in the phytoextraction sequence (Dessureault-Rompre et al., 2010; Liu et al., 2011). Many extractants have been used to estimate soil metal availability and the metals extracted by neutral salts and DGT have shown, in some circumstances, good relationships with metals in conventional crops and hyperaccumulators (Tandy et al., 2011; Menzies et al., 2007; Liu et al., 2011). The relationship between concentrations of metals measured in soils and in plants helps estimation of the necessary duration of repeated phytoextraction. Koopmans et al. (2008) considered that the time needed to clean metal contaminated soils ( $\mathrm{pH}$ 5.0-5.3) was based on a good linear relationship between the plant metal concentration and soil available metal (extracted with $0.01 \mathrm{M} \mathrm{CaCl}_{2}$ ). In the present study we also performed a correlation analysis between plant metal and soil available metal (measured by DGT and $\mathrm{NH}_{4} \mathrm{Ac} / \mathrm{CaCl}_{2}$ extraction) in the four metal contaminated soils with different properties during the repeated phytoextraction. Metals in plant shoots were well predicted by available metals in acid soils with the exception of weak prediction for Cd in DBS soil which had a low soil Cd concentration. In the case of the alkaline soils available metals failed to predict plant metals (Figs. 5 and 6). Plant metal concentrations usually depend on soil metal and the plant and also interactions between soil metal and the plant. The different relationships between soil available metal and plant metal in acid and alkaline soils may indicate different factors regulating plant metal uptake and accumulation. In acid soils the good prediction of plant metal by soil available metal during repeated phytoextraction may indicate that plant metal is affected largely by metal extractability in soil. In contrast, the poor correlation in alkaline soils might suggest that the plant and/or the effects of the rhizosphere on soil metal bioavailability are regulating factors. Soil metal bioavailability is related to two processes, soil metal desorption and biotic metal uptake processes (Peijnenburg et al., 1999). In alkaline soils with low soil solution metal concentrations, the roots of the hyperaccumulator may release some organic materials to increase metal desorption for uptake (Puschenreiter et al., 2005; Li et al., 2011). This effect may have made a large contribution to plant metal uptake in alkaline soils in this study. In addition, the decreases in metal extractability might do not change the processes of metal uptake by root and/or metal root to shoot translocation in alkaline sols during the repeated phytoextraction. These two processes sometimes are controlled by metal membrane transporter proteins (Rascio and Navari-Izzo, 2011). Although further studies are needed to confirm these explanations, here we can conclude that plant metal concentrations can be predicted on the basis of soil metal extractability in acid soils which have relatively high concentrations of available metal during the repeated phytoextraction, but not in alkaline soils with low available metal.

\subsection{Removal efficiencies of repeated phytoextraction based on total and available metal}

The purpose of phytoextraction of metal-contaminated agricultural soils is to remove excessive metal to recover the crop growing function of the soil for safe agricultural production. In our study seven crops of the hyperaccumulator were harvested over three years to remove metal from four contaminated soils. Metals showed large decreases in both acid and alkaline soils after phytoextraction but the decreases were much larger in the acid soils, with the highest decreases in $\mathrm{Cd}$ and $\mathrm{Zn}$ of 89 and 52\%, respectively, in acid soil (HLD), and lower in alkaline soils, especially in SLD with decreases in Cd and $\mathrm{Zn}$ of 37 and 12\% (Fig. 2). According to the Chinese Soil Environmental Standards (GB 1995-15618), the permissible levels of $\mathrm{Cd}$ and $\mathrm{Zn}$ in agricultural soils are less than 1.0 and $300 \mathrm{mg} \mathrm{kg}^{-1}(\mathrm{pH}>7.5)$, or 0.3 and $200 \mathrm{mg} \mathrm{kg}^{-1}(\mathrm{pH}<6.5)$, respectively. Taking these levels as phytoextraction targets, DBS soil has been remediated successfully (1 year); the other three soils still require further remediation. In HLD soil, as the plant metal uptake decreased with continuing remediation, the average daily uptake of the fifth and seventh crops was used to calculating the shortest remediation time. The remediation of $\mathrm{Zn}$ and $\mathrm{Cd}$ still required at least 0.9 and 1.2 years, respectively after the cease of this experiment. In SLD and ZJW soils, because the average daily uptake of Cd and $\mathrm{Zn}$ remained "constant" during the repeated phytoextraction, the values of average daily uptake of all crops excepting the fourth and sixth crops were used for calculation. The remediation of $\mathrm{Cd}$ and $\mathrm{Zn}$ in SLD still required 4.6 and 18.2 years respectively, and the ZJW soil needed 1.4 and 17.0 years after the cease of this experiment. These data indicate that it is possible to phytoextract $\mathrm{Cd} / \mathrm{Zn}$ from acid soils, but alkaline soils may require other or additional measures to enhance the metal availability for phytoextraction.

Previous workers have suggested that based on total metal removal from soils, one to several decades are needed using phytoextraction (Van Nevel et al., 2007; Koopmans et al., 2008), which is consistent with the phytoextraction of alkaline soils in this study. For security of crop production it may not be necessary to remove soil metal down to the threshold value as lowering of available metal might be sufficient. BSC-based phytoextraction aims at lowering the bioavailable metal from soils rather than depletion of the total metal concentration (Hamon and McLaughlin, 1999). The available metals estimated by the $\mathrm{CaCl}_{2} / \mathrm{NH}_{4} \mathrm{OAc}$-extractable fractions are based on equilibrium principles, whereas metal evaluation by DGT takes into consideration the kinetic re-supply from soil solids when metal is depleted in the soil solution. This mimics the processes of metal uptake in the rhizosphere (Davison et al., 2000). In the present study the DGT, $0.01 \mathrm{M} \mathrm{CaCl}_{2}$, and $1 \mathrm{M} \mathrm{NH}_{4} \mathrm{OAC}$ methods were used to estimate changes in soil available $\mathrm{Cd}$ and $\mathrm{Zn}$ during phytoextraction and to evaluate the removal efficiency of bioavailable metal. Compared to NP soil seven periods of phytoextraction decreased the available metals based on $\mathrm{CaCl}_{2}$ and $\mathrm{NH}_{4} \mathrm{OAc}$ extraction more in the acid than in the alkaline soils, with Cd showing larger effects than Zn (Fig. 3). For DGT after 
phytoextraction the decreases were $82-99 \%$ for $\mathrm{Cd}$ and $\mathrm{Zn}$ in all four soils (Fig. 3). In alkaline soils, the percentage decreases in available metals after phytoextraction were much higher than the percentage decreases in total metal concentrations (Figs. 2 and 3). The $R$ values suggest that the ability of the alkaline soils to resupply metals from solid phase to solution also decreased systematically after phytoextraction (Fig. 4). These results indicate that a phytoextraction target based on the BCS strategy could be adopted instead of a target based on total metals, especially for alkaline soils where total metal is not appreciably removed, but bioavailable metal is markedly lowered after repeated phytoextraction. However, in order to apply BCS in practice some questions need to be resolved (Fitz et al., 2003; Keller and Hammer, 2004; Koopmans et al., 2008). Firstly, the remediation targets should be defined at a level where the replenishment is very small so that the reduced bioavailable pools are sustainable. Secondly, it is necessary to evaluate the replenishment of bioavailable metal after the application of BCS, and thirdly there must be support from legislation, given that the existing legislation on soil remediation is still based on the total rather than the bioavailable metal pool.

\section{Conclusions}

Phytoextraction of metal-contaminated soils is a long-term process. In the repeated phytoextraction S. plumbizincicola accumulated high shoot concentrations of $\mathrm{Zn}$ in acid soils and high shoot concentrations of $\mathrm{Cd}$ in the heavily polluted acid soil in the early stages of sequential extraction, but shoot metal concentrations decreased substantially in the later stages of phytoextraction. Total concentrations in plants of $\mathrm{Cd}$ in lightly $\mathrm{Cd}$ polluted acid soil and $\mathrm{Cd}$ and $\mathrm{Zn}$ in alkaline soils showed no decreasing trend but the available metals, based on chemical extraction and DGT, decreased markedly. During phytoextraction soil available metal predicted metal uptake by the hyperaccumulator in heavily polluted acid soils, but not in lightly polluted acid soil or alkaline soils. After phytoextraction by seven consecutive crops of the hyperaccumulator the acid soils showed much higher total metal removal efficiency than the alkaline soils, indicating that successful total metal removal may be possible for acid soils. The DGT test showed the highest proportional removal of bioavailable metal with phytoextraction and it also demonstrated that the capacity of the alkaline soils to resupply metal from solid phase to solution declined systematically. This suggests that 'bioavailable contaminated stripping' (BCS) is a potentially useful strategy.

\section{Acknowledgements}

We thank the National Natural Science Foundation of China (41201300 and 40930739) and the National High-Technology Research and Development (863) Program of China (2012AA06A204 and 2012AA101402-2) for grant-aided support.

\section{References}

Assuncao, A.G.L., Martins, P.D., De Folter, S., Vooijs, R., Schat, H., Aarts, M.G.M., 2001 Elevated expression of metal transporter genes in three accessions of the metal hyperaccumulator Thlaspi caerulescens. Plant Cell Environ. 24, 217-226.

Davison, W., Zhang, H., 1994. In situ speciation measurements of trace components in natural waters using thin-film gels. Nature 367, 546-548.

Davison, W., Hooda, P.S., Zhang, H., Edwards, A.C., 2000. DGT measured fluxes as surrogates for uptake of metals by plants. Adv. Environ. Res. 3, 550-555.

Degryse, F., Smolders, E., Zhang, H., Davison, W., 2009. Predicting availability of mineral elements to plants with the DGT technique: a review of experimental data and interpretation by modelling. Environ. Chem. 6, 198-218.

Dessureault-Rompre, J., Luster, J., Schulin, R., Tercier-Waeber, M.L., Nowack, B., 2010. Decrease of labile $\mathrm{Zn}$ and $\mathrm{Cd}$ in the rhizosphere of hyperaccumulating Thlaspi caerulescens with time. Environ. Pollut. 158, 1955-1962.
Fitz, W.J., Wenzel, W.W., Zhang, H., Nurmi, J., Stipek, K., Fischerova, Z., Schweiger, P., Kollensperger, G., Ma, L.Q., Stingeder, G., 2003. Rhizosphere characteristics of the arsenic hyperaccumulator Pteris vittata L. and monitoring of phytoremoval efficiency. Environ. Sci. Technol. 37, 5008-5014.

Hamon, R.E., McLaughlin, M.J., 1999. Use of the hyperaccumulator Thlaspi cearulescens for bioavailable contaminant striping. In: Wenzel, W.W. et al. (Eds.) Proc. 5th International Conference on the Biogeochemistry of Trace Elements, pp. 908-909 (Vienna).

Huang, Z.Y., Chen, T., Yu, J.A., Zeng, X.C., Huang, Y.F., 2011. Labile Cd and $\mathrm{Pb}$ in vegetable-growing soils estimated with isotope dilution and chemical extractants. Geoderma 160, 400-407.

Keller, C., Hammer, D., 2004. Metal availability and soil toxicity after repeated croppings of Thlaspi caerulescens in metal contaminated soils. Environ. Pollut. 131, 243-254.

Kirkham, M.B., 2006. Cadmium in plants on polluted soils: effects of soil factors, hyperaccumulation, and amendments. Geoderma 137, 19-32.

Koopmans, G.F., Romkens, P.F.A.M., Fokkema, M.J., Song, J., Luo, Y.M., Japenga, J., Zhao, F.J., 2008. Feasibility of phytoextraction to remediate cadmium and zinc contaminated soils. Environ. Pollut. 156, 905-914.

Li, T.Q., Di, Z.Z., Yang, X.A., Sparks, D.L., 2011. Effects of dissolved organic matter from the rhizosphere of the hyperaccumulator Sedum alfredii on sorption of zinc and cadmium by different soils. J. Hazard. Mater. 192, 1616-1622.

Li, J.T., Baker, A.J.M., Ye, Z.H., Wang, H.B., Shu, W.S., 2012. Phytoextraction of Cdcontaminated soils: current status and future challenges. Crit. Rev. Environ. Sci. Technol. 42, 2113-2152.

Liang, H.M., Lin, T.H., Chiou, J.M., Yeh, K.C., 2009. Model evaluation of the phytoextraction potential of heavy metal hyperaccumulators and non-hyperaccumulators. Environ. Pollut. 157, 1945-1952.

Liu, F.J., Tang, Y.T., Du, R.J., Yang, H.Y., Wu, Q.T., Qiu, R.L., 2010. Root foraging for zinc and cadmium requirement in the $\mathrm{Zn} / \mathrm{Cd}$ hyperaccumulator plant Sedum alfredii. Plant Soil 327, 365-375.

Liu, L., Wu, L.H., Li, N., Luo, Y.M., Li, S.L., Li, Z., Han, C.L., Jiang, Y.G., Christie, P., 2011. Rhizosphere concentrations of zinc and cadmium in a metal contaminated soil after repeated phytoextraction by Sedum plumbizincicola. Int. J. Phytoremediation 13, 750-764.

Luo, J., Zhang, H., Zhao, F.J., Davison, W., 2010. Distinguishing diffusional and plant control of $\mathrm{Cd}$ and $\mathrm{Ni}$ uptake by hyperaccumulator and nonhyperaccumulator plants. Environ. Sci. Technol. 44, 6636-6641.

McGrath, S.P., Lombi, E., Gray, C.W., Caille, N., Dunham, S.J., Zhao, F.J., 2006. Field evaluation of $\mathrm{Cd}$ and $\mathrm{Zn}$ phytoextraction potential by the hyperaccumulators Thlaspi caerulescens and Arabidopsis halleri. Environ. Pollut. 141, 115-125.

Menzies, N.W., Donn, M.J., Kopittke, P.M., 2007. Evaluation of extractants for estimation of the phytoavailable trace metals in soils. Environ. Pollut. 145, 121-130.

Muhammad, I., Puschenreiter, M., Wenzel, W.W., 2012. Cadmium and Zn availability as affected by $\mathrm{pH}$ manipulation and its assessment by soil extraction, DGT and indicator plants. Sci. Total Environ. 416, 490-500.

Peijnenburg, W.J.G.M., Posthuma, L., Zweers, P.G.P.C., Baerselman, R., de Groot, A.C., Van Veen, R.P.M., Jager, T. 1999. Prediction of metal bioavailability in Dutch field soils for the oligochaete Enchytraeus crypticus. Ecotoxicol. Environ. Saf. 43, 170-186.

Puschenreiter, M., Schnepf, A., Millan, I.M., Fitz, W.J., Horak, O., Klepp, J., Schrefl, T., Lombi, E., Wenzel, W.W., 2005. Changes of Ni biogeochemistry in the rhizosphere of the hyperaccumulator Thlaspi goesingense. Plant Soil 271, 205-218.

Rascio, N., Navari-Izzo, F., 2011. Heavy metal hyperaccumulating plants: how and why do they do it? And what makes them so interesting? Plant Sci. 180, 169181.

Song, J., Zhao, F.J., Luo, Y.M., McGrath, S.P., Zhang, H., 2004. Copper uptake by Elsholtzia splendens and Silene vulgaris and assessment of copper phytoavailability in contaminated soils. Environ. Pollut. 128, 307-315.

Tandy, S., Mundus, S., Yngvesson, J., de Bang, T.C., Lombi, E., Schjoerring, J.K. Husted, S., 2011. The use of DGT for prediction of plant available copper, zinc and phosphorus in agricultural soils. Plant Soil 346, 167-180.

Van Nevel, L., Mertens, J., Oorts, K., Verheyen, K., 2007. Phytoextraction of metals from soils: how far from practice? Environ. Pollut. 150, 34-40.

Whiting, S.N., Leake, J.R., McGrath, S.P., Baker, A.J.M., 2000. Positive responses to Zn and $\mathrm{Cd}$ by roots of the $\mathrm{Zn}$ and $\mathrm{Cd}$ hyperaccumulator Thlaspi caerulescens. New Phytol. 145, 199-210.

Williams, P.N., Zhang, H., Davison, W., Zhao, S.Z., Lu, Y., Dong, F., Zhang, L., Pan, Q., 2012. Evaluation of in situ DGT measurements for predicting the concentration of $\mathrm{Cd}$ in Chinese field-cultivated rice: impact of soil Cd: Zn ratios. Environ. Sci. Technol. 46, 8009-8016.

Wu, L.H., Zhou, S.B., Bi, D., Guo, X.H., Qin, W.H., Wang, H., Wang, G.J., Luo, Y.M., 2006. Sedum plumbizincicola, a new species of the Crassulaceae from Zhejiang, China. Soils 38, 632-633 (in Chinese).

Wu, L.H., Li, N., Luo, Y.M., 2008. Phytoextraction of heavy metal contaminated soil by Sedum plumbizincicola under different agronomic strategies. In: Proc $5^{\text {th }}$ Int Phytotechnol. Conf, pp, 49-50.

Wu, L.H., Liu, Y.J., Zhou, S.B., Guo, F.G., Bi, D., Guo, X.H., Baker, A.J.M., Smith, J.A.C., Luo, Y.M., 2013. Sedum plumbizincicola X.H. Guo et S.B. Zhou ex L.H. Wu (Crassulaceae): a new species from Zhejiang Province, China. Plant Syst. Evol. 299, 487-498.

Yanai, J., Zhao, F.J., McGrath, S.P., Kosaki, T., 2006. Effect of soil characteristics on Cd uptake by the hyperaccumulator Thlaspi caerulescens. Environ. Pollut. 139, 167-175.

Zhang, H., Davison, W., 1995. Performance-characteristics of diffusion gradients in thin-films for the in-situ measurement of trace-metals in aqueous-solution. Anal. Chem. 67, 3391-3400. 